\title{
A Hub intervention in Surrey, Canada: learning from people at risk
}

\author{
Stefanie N. Rezansoff, ${ }^{*}$ Akm Moniruzzaman,* Wei Xiao Yang, ${ }^{*}$ and Julian M. Somers*
}

\begin{abstract}
Co-occurring health and public safety concerns involving mental illness, substance use, and homelessness are increasingly prevalent challenges for policymakers in cities worldwide. The Hub model is a roundtable process where the combined resources of diverse agencies are used to mitigate urgent risk of crime, victimization, illness and death, by establishing immediate connections with appropriate services and supports. Initiated in Scotland, the model has been replicated in more than 60 communities across Canada since 2012. In November 2105, the Surrey Mobilization and Resiliency Table (SMART) became the first Hub in British Columbia. Little peer-reviewed research has examined the impact of Hub interventions from a client perspective. We conducted semi-structured interviews with 16 SMART clients and analyzed their responses thematically. We also examined demographic- and intervention-related characteristics reported in the SMART database. Participants described positive experiences with SMART service providers, and commented that the intervention was effective at meeting relatively circumscribed needs. However, most clients reported complex and mutually exacerbating health and social conditions, and expressed the need for ongoing structured support (e.g., Assertive Community Treatment (ACT)). Our results emphasize the beneficial role played by SMART's coordinated, real-time approach. They also indicate demand for social policies that include substantial and enduring forms of support to prevent crises and promote community safety.
\end{abstract}

Key Words Hub; concurrent disorders; public safety; homelessness; problem-oriented policing; Assertive Community Treatment.

Journal of CSWB. 2018 Oct;3(2):47-51 www.journalcswb.ca

\section{INTRODUCTION}

In Canada, crime rates have declined consistently for more than two decades (Statistics Canada, 2017), while law enforcement costs have increased (Di Matteo, 2014; Leuprecht, 2014). Police, courts, and departments of corrections are increasingly required to respond to complex, co-occurring, and mutually exacerbating health and public safety issues involving mental illness, substance use, and homelessness (Fazel \& Danesh, 2002; Somers, Moniruzzaman, Rezansoff et al., 2014). In response, a number of Canadian communities have implemented an initiative known as the Hub model or Situation Table, ${ }^{1}$ where the combined resources of multisectoral agencies (e.g., policing, mental health, addictions, housing, education and corrections) are used to identify and respond in a timely manner to situations of 'acutely elevated risk $^{\prime 2}$ of harm to individual and/or public health and safety. The first application of the Hub model in the province of British Columbia is the Surrey Mobilization and Resiliency Table (SMART), implemented in November 2015.

Situation Tables (STs) respond to clients with diverse risk factors, and interaction with the justice system is not necessary for referral. Rather than serving as stand-alone programs, they function as forums where agency representatives convene for time-limited discussions of high-risk situations. Finally, ST interventions are limited to crisis resolution, and do not include sustained support such as case management or Assertive Community Treatment.

Little is known about client perspectives and experiences of ST interventions, an omission that has been identified as requiring attention (Nilson, 2016). The current study aimed to address this gap by conducting semi-structured interviews with SMART clients, focusing on their needs, their experiences with SMART, and the factors that enable or impede lasting positive change.

Referring to the formalized process of information sharing between table discussants from social, health, and housing agencies, community stakeholders, and police during regularly scheduled meetings. The terms Hub and Situation Table are used interchangeably in extant literature and the current manuscript.

2 Defined by four criteria (from McFee \& Taylor, 2014, p.10): a) significant community interest at stake; b) clear probability of harm; c) severe intensity of harm predicted; and d) multidisciplinary nature to elevated risk factors. 


\section{METHODS}

\section{The SMART Database}

SMART maintains a de-identified client database modelled on Canada's flagship Hub (Nilson, 2014). Recorded data include client socio-demographic characteristics, categories of risk, agency involvement, services mobilized, intervention outcomes, and length of client engagement with SMART. These data were tabulated and analyzed to provide supplementary context for the interview findings.

\section{Interviews}

Interview eligibility was based on current or former SMART client status, regardless of the extent of client engagement with services. Recruitment was facilitated by SMART service providers affiliated with police, income assistance, housing, health care, corrections, education, and civic government in Surrey. Recruitment was conducted purposively to identify clients whose needs were representative of those in the overall population served by SMART, and continued to the point of theoretical saturation whereby the responses of participants were overlapping and reiterative. No inferential tests were planned, and statistical power was not calculated. Table members drew on their knowledge of clients' whereabouts to facilitate contact with the research team. Participation was voluntary and did not affect service provision.

Consenting participants met with a trained postdoctoral interviewer who explained study objectives and obtained written permission for interviews to be recorded and transcribed. A semi-structured interview was conducted targeting: a) immediate needs; b) experience with SMART; and c) barriers/contributors to changes initiated by SMART. Interviews took place in agency offices, custody centres, and street settings, and lasted from 15 to 30 minutes. A cash honorarium of $\$ 25.00 \mathrm{CDN}$ was provided.

Interviews were transcribed and anonymized. Transcripts were reviewed independently by two researchers, and recurring themes for each domain were identified using systematic text condensation (Malterud, 2012). A coding frame was developed to facilitate the coding of interview transcripts using NVivo (Version 11.0). Final identification of themes was based on consensus between four authors. Pseudonyms were used in reporting. This study was reviewed and approved by the Research Ethics Board at Simon Fraser University.

\section{RESULTS}

\section{Client Characteristics}

Demographic and intervention-related client characteristics $(n=161)$ extending from November 2015 (SMART inception) August 2017 are presented in Table 1.

The majority of cases were single clients (93\%) between the ages of 25 and 49 (77\%). Although gender was evenly divided across the population, individuals under the age of 25 were more likely to be female (65\%). Cases originated most frequently from police, probation, and housing outreach services, and were resolved within a mean period of 2-3 weeks. Half of all case closings were attributed to client engagement with appropriate services and supports. A minority (14\%) of individuals and one family refused services. Nine (individual) client cases (6\%) were re-opened at least once.
TABLE I Socio-demographic and intervention-related characteristics of SMART clients $\left(n=161^{\circ}\right)$

\begin{tabular}{|c|c|c|c|}
\hline & $\begin{array}{c}\text { Individual } \\
\text { (youth) } \\
n=51^{b}\end{array}$ & $\begin{array}{c}\text { Individual } \\
\text { (adult) } \\
n=96\end{array}$ & $\begin{array}{c}\text { Family } \\
n=12\end{array}$ \\
\hline \multicolumn{4}{|l|}{ Age } \\
\hline$<25$ years & $51(100.0)$ & $0(0.0)$ & \\
\hline $25-49$ years & $0(0.0)$ & $74(77.1)$ & \\
\hline$\geq 50$ years & $0(0.0)$ & $22(22.9)$ & N/A \\
\hline \multicolumn{4}{|l|}{ Gender } \\
\hline Female & 33 (64.7) & $39(40.6)$ & \\
\hline Male & 18 (35.3) & 57 (59.4) & N/A \\
\hline \multicolumn{4}{|l|}{ Originating Agency } \\
\hline Education - school district & † 8 (15.7) & $0(0.0)$ & $4(33.3)$ \\
\hline Local health authority & $2(3.9)$ & $7(7.3)$ & $1(8.3)$ \\
\hline Housing \& outreach & $10(19.6)$ & $29(30.2)$ & $3(25.0)$ \\
\hline Income assistance & $1(2.0)$ & $4(4.2)$ & $0(0.0)$ \\
\hline Community services & $1(2.0)$ & $1(1.0)$ & $0(0.0)$ \\
\hline Police & $22(43.1)$ & $36(37.5)$ & 2 (16.7) \\
\hline Probation - Adult & $5(9.8)$ & 17 (17.7) & $0(0.0)$ \\
\hline Social services & $2(3.9)$ & $2(2.1)$ & $2(16.7)$ \\
\hline \multicolumn{4}{|l|}{ Duration of Intervention ${ }^{c}$} \\
\hline Mean (SD) & $17.8(13.0)$ & $16.3(11.9)$ & $21.0(7.3)$ \\
\hline Median (min, max) & $14(0,49)$ & $14(0,56)$ & $21(7,28)$ \\
\hline \# of repeating clients & $3(5.9)$ & $6(6.2)$ & $0(0.0)$ \\
\hline
\end{tabular}

Categories of risk for the client population as assessed by SMART are presented in Table 2 . The most prevalent category of risk was a high level of unmet basic need (e.g., housing, activities of daily living; 51\%), followed by exposure to negative environment (e.g., physical or emotional abuse; $16 \%$ ), and substance use (alcohol or other drugs; 14\%). Crime (gang involvement or other criminal behaviour) and mental/ physical health (disability, diagnosed disorder) were noted as risk factors in 10 per cent and 8 per cent of cases, respectively.

\section{Interview Sample}

Of 28 individuals who were approached for an interview, 16 provided informed consent (10 elected not to participate, 2 were deemed by the investigators to be unable to consent). Self-reported characteristics of the interview sample were similar to those of the larger client population, and are presented in Table 3. The majority of participants were white $(n=9)$ and male $(n=10)$, with a mean age of 36 years. Six participants claimed Indigenous ethnicity. More than half were homeless and reported diagnosed mental disorder, current substance use, and chronic physical illness/injury. Five individuals had children under the age of 18 , and one participant was pregnant.

\section{Interview Findings}

Results are organized under the following domains: client needs: experience with the SMART intervention; and barriers/contributors to positive change. Subheadings refer to 
TABLE II Assessed categories of risk among SMART clients ( $n=161^{1}$ )

\begin{tabular}{|c|c|c|c|}
\hline & $\begin{array}{c}\text { Individual } \\
\text { (youth) } \\
n=51\end{array}$ & $\begin{array}{c}\text { Individual } \\
\text { (adult) } \\
n=96\end{array}$ & $\begin{array}{c}\text { Family } \\
\mathrm{n}=12\end{array}$ \\
\hline \multicolumn{4}{|l|}{ Primary risk category } \\
\hline Basic needs & $26(51)$ & 47 (49) & $8(66.7)$ \\
\hline Crime \& public safety & $3(5.9)$ & $11(11.5)$ & $2(16.7)$ \\
\hline Alcohol/drugs & $9(17.6)$ & $13(13.5)$ & $1(8.3)$ \\
\hline Mental health & $5(9.8)$ & $4(4.2)$ & $0(0)$ \\
\hline Negative environment & 8 (15.7) & 17 (17.7) & $1(8.3)$ \\
\hline Physical health & $0(0)$ & $4(4.2)$ & $0(0)$ \\
\hline \multicolumn{4}{|c|}{$\begin{array}{l}\text { ane individuals were repeat clients. Information was missing for two } \\
\text { clients. }\end{array}$} \\
\hline \multicolumn{4}{|c|}{$\begin{array}{l}\text { TABLE III Self-reported socio-demographic, health, and related } \\
\text { characteristics of SMART interviewees }(n=16)\end{array}$} \\
\hline \multicolumn{2}{|l|}{ Variable } & \multicolumn{2}{|c|}{ n (\%) } \\
\hline \multicolumn{2}{|l|}{ Age } & \multicolumn{2}{|c|}{36 years; $(S D=14)$} \\
\hline \multicolumn{2}{|l|}{ Gender (M) } & \multicolumn{2}{|c|}{$10(63)$} \\
\hline \multicolumn{4}{|l|}{ Ethnicity } \\
\hline - Indigenous & & \multicolumn{2}{|c|}{$6(38)$} \\
\hline - White & & \multicolumn{2}{|c|}{$9(56)$} \\
\hline - Other & & \multicolumn{2}{|c|}{$1(6)$} \\
\hline Dx physical illness & & \multicolumn{2}{|c|}{$8(50)$} \\
\hline Dx mental disorder & & \multicolumn{2}{|c|}{$10(63)$} \\
\hline Current substance use & & \multicolumn{2}{|c|}{$12(75)$} \\
\hline Currently homeless & & \multicolumn{2}{|c|}{$10(63)$} \\
\hline Dependent children & & \multicolumn{2}{|c|}{$1(6)$} \\
\hline Children in foster care & & \multicolumn{2}{|c|}{$4(25)$} \\
\hline Currently pregnant & & \multicolumn{2}{|c|}{$1(6)$} \\
\hline
\end{tabular}

dominant themes identified through the analysis of transcripts, prominently involving: shelter/housing, substance use, coordination across sectors, and longer-term support.

\section{Client Needs}

Self-described needs emphasized: housing, personal safety, and substance dependence. Housing affordability and accessibility were prominent challenges. To illustrate, Mary-a single Indigenous woman recently released from hospital following the birth of her son-had attempted to secure an apartment:

"I need affordable housing first of all. Rent is too high, landlords are restricting, and they're somewhat prejudiced too ... about your background or what you do for a living."

In many cases clients described interdependent needs (e.g., housing linked to drug treatment). For example, Josh and his partner had been placed in a shelter, but were subsequently evicted for drug use:

“It was a good place for us, but it just didn't work ... we fucked up and got the boot. A recovery house, or something like that, would have been better."
Josh explained how renting an apartment was financially impossible for them, despite their combined resources:

"It's hard. It's really hard. Even with both our incomes it's hard to find a place. Both our whole cheques would go to them [landlord], and we'd get like, what, thirty bucks or something to eat for the month, right?"

Threats to personal safety often involved interactions between drug use and sleeping rough. Fifty-year old Suzanne described the following attack:

"It was one of the young guys on the strip that deals and stuff, and he was high and drunk ... he ripped open the zipper to the tent, grabbed the propane tank [next to me] and started swinging, you know? Broke my nose, fractured my orbital bone and all kinds of stuff ... It's dangerous out there. And you have to look after yourself... Especially for ladies and the older guys."

Jenny was five months pregnant at the time of the interview, and described her circumstances sleeping in a tent on the street:

"I'm so tired ... I can't sleep during the day. We have to collapse our tents by 9 o'clock in the morning ... If you sleep inside the tent during the day you suffocate in the sun. It's really hot - you're basically, like, in a greenhouse ... No, I don't want to be there ... I hate it down there, I do ... I hate it. There's lots of rats. They like, chew through your tents and everything. So gross."

Participants spoke urgently and desperately of their need to curtail substance use, and their frustrated attempts to access treatment either initially or after a prior episode:

“Ever since 2006 I've been using crystal meth and it's just such a shit show. I've lost lots, right? I tried Suboxone ... I had another puff and I was right back into it. Like, I've never used intravenous, and I never will. Knock on wood or whatever, right? But you know, I feel that it's only getting closer and closer, and I don't want to go there... Yeah man. I gotta get the fuck outta here man."

\section{Experience with the SMART Intervention}

Participants described benefits derived from their SMART encounters. These included advocacy with landlords to secure housing. Rob, a 46-year-old Indigenous man related:

"Housing I could never get by myself. I just, you know, just...maybe I'm a visible minority or something, I don't know. Like even if I clean myself up it seems like, I don't get through, eh? It's hard if you don't have references too, right? You know. So yeah...it was helpful."

Some participants had relatively discrete needs. Paul described how he and his five-year-old son were helped by gaining access to income assistance:

"I didn't need anything else - just help getting back on my feet and making a home for my son. We were living 
in a motel, and the Ministry was going to take him away, but once I had some money I was able to find us a place on my own. Now I can start looking for work and we can get on with things."

Other participants described benefits related to advice and encouragement provided by SMART. Eighteen-year-old James explained how he was frequently arrested for fighting, behaviour that he attributed to poor medication adherence:

"They talked me into taking my meds again, and I'm fighting way less... And they showed me the clinic for my Narcan kit. I'm there once a week now."

\section{Barriers and Contributors to Change}

Participants consistently valued the attention that they received from SMART, and described this as an important contributor to change. The qualities of persistence and caring often stood out:

"It felt really good to get help from Dan [police officer]. I'm grateful. He was ok to talk to and he kept everything confidential ... He stuck with me. I can still talk to him ... They tried to help me right away, and I pushed them away, but they just came trying to help me again."

Participants singled out police representatives of SMART, describing their approach as fundamentally different from their previous experiences with law enforcement:

"It was cool. I never met a cop that would go that far, you know what I mean? Like, he seemed to take it a bit personal. And it was cool because, like, I don't know - he took a shine to me too - I swear ... even came off-shift to see me in the hospital, right? Like, it was just cool - they took it a bit further than the street, right? Took it home with them almost. It was like, it was a really cool feeling ... it was motivating."

Respondents emphasized that their experience with SMART made them more willing to engage with service providers and more motivated to make the most of opportunities that are presented to them:

"The tunnel seems a lot less ... long. You know what I mean? The light's like, right there! Just now I gotta make the next step, right? I was there for a minute and I liked it, and I need to go back, man."

Barriers to change primarily involved missing or incomplete services (e.g., abstinence-based housing without conjoint drug treatment). Forty-eight-year-old Bert praised SMART for helping him access an emergency shelter, but expressed remorse that his heroin dependence undermined that opportunity:

"She was really good ... she got me into [the shelter] but it didn't work out due to the fact uh...with the curfew and stuff. I just kind of screwed that up, cause like I said ... I was using quite a bit at that time. But she did a lot to help me-I'll tell you that. She could have done a lot more for me if I hadn't been so...like, you know. I was doing a lot of drugs then, right? It's kind of embarrassing but, I probably should have stuck more with her, you know what I mean? And I didn't and I regret that."

Similarly, Danielle-an elderly diabetic_explained that SMART helped her find an apartment, but that she felt compelled to return to the street:

"They put me in a place - a sort of transit never-neverland. Sometimes you just can't...that was a huge problem for me with my cellulitis, right? ... I was supposed to go to the Dr's office for IV treatment, 3 hours a day. But I couldn't get there - I couldn't walk to Skytrain because um, my legs were...right? And so the ambulance guys - the EMTs that are on the strip now - they insisted on taking me, like every 3 days."

Despite describing benefits arising from their contact with SMART, the vast majority reported that it was insufficient to meet ongoing challenges. Tony, a 50-year-old homeless woman with chronic health issues and heroin dependence had a very clear idea of her long-term support needs:

"I need an ACT team. I need a proper worker to sit down and remain ... to constantly communicate with me and - what I need is not that hard! [Crying] I need a contact number, a contact person, you know? I need supportive housing and I need to get on the methadone program - really bad."

\section{DISCUSSION}

Our findings indicate that participants derived meaningful support from SMART, and that consistent needs for support transcended variations in their personal circumstances. Overall, participants' self-reported priorities involved homelessness, substance use, personal safety, and unmet basic needs. Nearly all clients reported needs spanning multiple domains of service (e.g., housing, health care, as well as income support). Notably, participant self-reported substance use $(75 \%)$ was much higher than the level of substance use recorded in the SMART database (14\%), a discrepancy that may arise from the fact that SMART does not conduct clinical assessments.

Housing emerged as the paramount need among SMART clients. Typically, housing was linked to additional needs, such as transit or addiction treatment. Clients reported losing housing due to non-compliance with regulations (e.g., curfews, abstinence requirements). Few participants emphasized needs related to mental or physical health. It is unclear whether participants were unaware of their health status (e.g., infection positivity, mental illness symptoms, etc.), regarded their physical and mental health as lower priorities, or lacked positive and therapeutic experiences with relevant health professionals. People claiming Indigenous ethnicity comprised 38 per cent of the sample, underscoring the need for culturally appropriate services.

Participants reported two primary sources of benefit from their encounters with SMART. In some cases the 
provision of specific resources enabled other positive changes to take place. This occurred when clients had relatively circumscribed needs. However, the majority stated that essential services and supports were unavailable (e.g., substance use treatment, affordable housing).

The second type of benefit involved clients' experiences with SMART representatives. Clients described SMART as having provided them with attention and opportunities that they would not otherwise have received. Clients articulated feeling hopeful following their encounters with SMART, and appreciative of the care and concern shown by table members. Participants reported valuing their relationships with team members even after their cases were closed, but missing the level of support they received as active clients. Expressions of gratitude were prevalent among interviewees who remained homeless and at risk.

Our findings support the role of brief interventions like SMART in the identification of high-risk cases, diversion from acute risk, and rapport building with extremely marginalized people. Nonetheless, the de-escalation of imminent risk of harm is not a solution to the longstanding and complex social problems described by former SMART clients. To promote enduring reductions in risk Situation Tables (ST) require access to long-term resources specific to the needs of their community. In the case of SMART these needs emphasize appropriate housing.

The current study provides preliminary evidence concerning clients' experiences with ST interventions, augmented with descriptive data collected by SMART. Although Table members attested to the representativeness of our sample, we are unable to confirm this independently. We are also unable to validate the self-reports of participants. A further potential limitation of this research concerns the generalizability of our findings to other communities due to differences in client needs and available resources.

Several research questions addressing the ST model require investigation, including mechanisms to pair acute interventions with continuing evidence-based supports (e.g., Assertive Community Treatment). The study of long-term outcomes for clients of ST interventions is also required, including research on the patterns and costs of service use preceding clients' involvement with STs, the conditions required to achieve diversion from acute risk, and the resources needed for long-term recovery.

\section{CONCLUSIONS}

This study set out to learn from people who are at risk, and found that the SMART intervention attenuated acute crises, established rapport, and inspired hope among highly marginalized people. SMART effectively triaged cases based on acuteness of risk, but was limited by the insufficient availability of evidence-based models of housing and support. A robust body of evidence details the types of services that are effective, and develops the business case for their implementation. Scaling up these services to meet demand is now a matter to be resolved by elected officials and the public servants who support them.

\section{ACKNOWLEDGMENTS}

This research was supported by a grant from the City of Surrey, British Columbia, Canada. The authors thank all study participants for their time, openness and advice. Invaluable assistance was provided by SMART discussants who facilitated interviews and shared their expertise throughout the study. Additional expertise and leadership was provided by SMART executive members. Finally, the authors would like to thank the City of Surrey for their overall support of this project. Opinions, points of view and any mistakes are the authors' alone.

\section{CONFLICT OF INTEREST DISCLOSURES}

The authors declare that there are no conflicts of interest.

AUTHOR AFFILIATIONS

*Faculty of Health Sciences, Simon Fraser University, Burnaby, BC, Canada.

\section{REFERENCES}

Di Matteo, L. (2014). Police and crime rates in Canada: a comparison of resources and outcomes. Vancouver, BC: The Fraser Institute. Retrieved from the Fraser Institute website: https://www.fraserinstitute.org/sites/ default/files/police-and-crime-rates-in-canada.pdf

Fazel, S. \& Danesh, J. (2002). Serious mental disorder in 23,000 prisoners: a systematic review of 62 surveys. The Lancet, 359, 545-550.

Leuprecht, C. (2014). The blue line or the bottom line of police services in Canada? Arresting runaway growth in costs. Ottawa, ON: The Institute. Retrieved from the Macdonald-Laurier Institute for Public Policy website: http://www.macdonaldlaurier.ca/files/pdf/MLl_CostofPolicing_Final. pdf

Malterud, K. (2012). Systematic text condensation: a strategy for qualitative analysis. Scandinavian Journal of Public Health, 40,795-805.

McFee, D., \& Taylor, N. (2014). The Prince Albert Hub and the emergence of Collaborative Risk-Driven Community Safety. (Change and innovation in Canadian policing-Canadian Police College Discussion Paper Series). Ottawa, ON: Canadian Police College. Retrieved from the Government of Canada Publications website: http://publications.gc.ca/ site/eng/9.832291/publication.html

Nilson, C. (2014). Risk-driven Collaborative Intervention: a preliminary impact assessment of Community Mobilization Prince Albert's Hub Model. Saskatoon, SK: University of Saskatchewan. Retrieved from the University of Saskatchewan Centre for Forensic Behavioural Science and Justice Studies website: https://www.usask.ca/cfbsjs/research/pdf/ research_reports/RiskDrivenCollaborativelntervention.pdf

Nilson, C. (2016). Canada's Hub Model: Calling for perceptions and feedback from those clients at the focus of Collaborative Risk-Driven Intervention. Journal of Community Safety and Wellbeing, 1, 58-60.

Somers, J. M., Moniruzzaman, A., Rezansoff, S. N., \& Patterson, M. (2014). Examining the impact of case management in Vancouver's Downtown Community Court: a quasi-experimental design. PLoS One, 9, e90708.

Statistics Canada. (2017). Canada's crime rate: two decades of decline. Ottawa, ON: Statistics Canada. Retrieved from the Statistics Canada website: http://www.statcan.gc.ca/pub/11-630-x/11-630-x2015001eng.htm 